\title{
Injection device-related risk management toward safe administration of medications: experience in a university teaching hospital in The People's Republic of China
}

This article was published in the following Dove Press journal:

Therapeutics and Clinical Risk Management

17 March 2014

Number of times this article has been viewed

\author{
Ling-ling Zhu' \\ Wei $\mathrm{Li}^{2}$ \\ Ping Song ${ }^{3}$ \\ Quan Zhou ${ }^{3}$ \\ 'Geriatric VIP Ward, Division of \\ Nursing, ${ }^{2}$ Division of Medical \\ Administration, ${ }^{3}$ Department of \\ Pharmacy, the Second Affiliated \\ Hospital, School of Medicine, \\ Zhejiang University, Hangzhou, \\ People's Republic of China
}

Correspondence: Quan Zhou Department of Pharmacy, the Second Affiliated Hospital, School of Medicine, Zhejiang University, Hangzhou 310009 ,

Zhejiang Province, People's

Republic of China

Tel +8657187783690

Fax +86 57I 87022776

Email zhouquan142602@zju.edu.cn

\begin{abstract}
The use of injection devices to administer intravenous or subcutaneous medications is common practice throughout a variety of health care settings. Studies suggest that one-half of all harmful medication errors originate during drug administration; of those errors, about two-thirds involve injectables. Therefore, injection device management is pivotal to safe administration of medications. In this article, the authors summarize the relevant experiences by retrospective analysis of injection device-related near misses and adverse events in the Second Affiliated Hospital of Zhejiang University, School of Medicine, Zhejiang University, People's Republic of China. Injection device-related near misses and adverse events comprised the following: 1) improper selection of needle diameter for subcutaneous injection, material of infusion sets, and pore size of in-line filter; 2) complications associated with vascular access; 3 ) incidents induced by absence of efficient electronic pump management and infusion tube management; and 4) liquid leakage of chemotherapeutic infusion around the syringe needle. Safe injection drug use was enhanced by multidisciplinary collaboration, especially among pharmacists and nurses; drafting of clinical pathways in selection of vascular access; application of approaches such as root cause analysis using a fishbone diagram; plan-do-check-act and quality control circle; and construction of a culture of spontaneous reporting of near misses and adverse events. Pharmacists must be professional in regards to medication management and use. The depth, breadth, and efficiency of cooperation between nurses and pharmacists are pivotal to injection safety.
\end{abstract}

Keywords: electronic infusion pump, infusion therapy, intravenous, medication errors, subcutaneous injection, vascular access

\section{Introduction}

The use of injection devices to administer intravenous (IV) or subcutaneous medications is common practice throughout a variety of health care settings. The risks associated with such practice are wide and varied. ${ }^{1}$ Studies suggest that one-half of all harmful medication errors originate during drug administration; of those errors, about twothirds involve injectables. ${ }^{2,3}$ Errors associated with IV medication administration can result in severe or life-threatening adverse drug events. The majority of these medication incidents are attributable to human error. ${ }^{4}$ It is necessary to establish consistent, simple, and clear health professional education on the care and maintenance of IV devices in compliance with guidelines and recommendations. ${ }^{5}$ Injection device management is pivotal to safe administration of medications. 
To our knowledge, an up-to-date review on medication errors due to inappropriate selection and improper use of injection devices is not currently available. Also, experience in injection device management toward safe administration of medications has not been well documented in the scientific literature.

All hospitals receiving Joint Commission International (JCI) accreditation should pay special attention to safe injection practices. The Second Affiliated Hospital of Zhejiang University, School of Medicine, Zhejiang University, People's Republic of China (SAHZU) successfully passed the JCI accreditation as an academic medical center hospital on February 24, 2013. SAHZU performed continuous quality improvements in safe medication administration throughout the process of acquiring JCI accreditation. The aims of this article are to summarize relevant experiences in injection device-related risk management toward safe drug administration by retrospective analysis of medication incidents and to provide some reference for international counterparts.

\section{Needle diameter for subcutaneous injection}

Appropriate device selection in subcutaneous administration is an important contributing factor to patient safety and comfort. ${ }^{6}$ Previous studies have shown that a thinner needle causes fewer occurrences of painful needle insertions and a smaller amount of backflow. ${ }^{7-9}$ Therefore, thinner needles for subcutaneous administration are continuously developed and are generally recommended in clinical practice.

However, cases in our hospital reminded us that needle size for subcutaneous injection was also associated with formulation characteristics of the medication. In April 2013, our pharmacy received a complaint from the head nurse of the gynecology ward, who reported that blockage of the syringe needle usually occurred during subcutaneous injection of $3.75 \mathrm{mg}$ sustained-release leuprolide acetate microspheres (ENANTONE ${ }^{\circledR}$ ) (Takeda Pharmaceutical Company Limited, Osaka, Japan), a gonadotropin-releasing hormone analog agonist. Nurses suspected the formulation of quality defects. A clinical pharmacist investigated the adverse events and found that the culprit was improper selection of needle diameter. In the People's Republic of China, the outer diameter of a needle for subcutaneous administration of $2 \mathrm{~mL}$ of solution is generally size 6 (ie, $0.6 \mathrm{~mm}$ ), and that for $1 \mathrm{~mL}$ of solution is generally size 5 (ie, $0.5 \mathrm{~mm}$ ). Nurses used size 6 needles for subcutaneous administration after reconstituting the leuprolide powder with $2 \mathrm{~mL}$ of solvent, whereas the package insert ${ }^{10}$ of this medication clearly states that a needle of at least size 7 (ie, outer diameter
$0.7 \mathrm{~mm}$, equivalent to 22 gauge) is required. Embarrassingly, no one in the pharmacy had read it carefully before and thus did not have this knowledge. Since then, leuprolide acetate microspheres dispensed by pharmacy must be manually relabeled with an alert regarding appropriate needle-size selection before subcutaneous injection. No similar adverse events occurred after following the right directions.

Cilurzo et al proposed a method of scoring the needlesyringe formulation system to rationalize and support the selection of optimal diameter and length of needle. ${ }^{11}$ It is noticeable that the thinner the needle diameter, the higher the dynamic glide force and maximum force values. Only when the maximum force values are lower than $125 \mathrm{mPa}$ does an injection go smoothly. ${ }^{10}$ Therefore, syringeability and injectability concepts in subcutaneous administration are of particular significance for specialized dosage forms such as injectable emulsions, suspensions, liposomes, microemulsions, and microspheres. It is worth mentioning that, in drug administration of these formulations, problems of correct needle selection have been overcome in some countries by manufacturers supplying medications in prefilled syringes that come with the correct-size needles.

\section{Composition of infusion sets}

Special infusion sets are needed for IV administration of some medications. Bis (2-ethylhexyl)phthalate (DEHP) is a possible hepatotoxin, carcinogen, teratogen, and mutagen. It is well known that DEHP may be more easily leached from polyvinyl chloride (PVC) infusion bags and PVC administration sets by some formulation excipients like Polysorbate 80 (the presence of polysorbate 80 in etoposide injection could induce substantial amounts of DEHP leaching from PVC infusion bag into etoposide infusion), ${ }^{12}$ ethanol, propanediol, and polyethylene castor oil. ${ }^{13,14}$ As described in their prescribing information, PVC material sets must not be used for infusion of products containing polyethylene oxide ethyl castor oil (eg, paclitaxel, cyclosporine, teniposide). ${ }^{15-17}$ As an alternative formulation of paclitaxel, paclitaxel-loaded polymeric micelles, made of monomethoxy poly(ethylene glycol)-block-poly(d,l-lactide) diblock copolymer, has demonstrated clear therapeutic advantages over Taxol ${ }^{\circledR}$ (paclitaxel injection; Bristol-Myers Squibb, New York, NY, USA), the most commonly used paclitaxel formulation containing 1:1 blend of polyethoxylated castor oil and dehydrated ethanol. A study has shown that there is negligible risk of DEHP exposure from diluted paclitaxel-loaded polymeric micelle IV infusion using PVC infusion bags and PVC administration sets. ${ }^{18}$ Polyethylene (PE) material infusion sets are alternatives of products 
containing pure PVC, coextruded composite (PE/PVC), or triple-layered composite (PVC/ethyl vinyl acetate/PE). ${ }^{19}$ Furthermore, in view of significant drug adsorption by PVC, infusion of the following medications needs non-PVC sets: insulin, nimodipine, nitroglycerin, amiodarone, human coagulation factor VIII, diazepam, fentanyl, sufentanil, and vitamin A. ${ }^{20-26}$ As described in the prescribing information, nimodipine IV solution (Bayer AG, Leverkusen, Germany) ${ }^{21}$ is incompatible with infusion bags and any administration sets made of PVC, but it is compatible with glass infusion bottles and infusion packs made of PE. PE tubes are supplied with this medication. Considering these situations, SAHZU introduced disposable PE infusion sets in April 2013. The pharmacy drafted a list of medications that need non-PVC infusion sets and was required to note specific alerts on the labels of infusions prepared by the pharmacy intravenous admixture service center (PIVAS).

Additionally, lipid emulsion is unstable in PVC infusion sets. Bagel et al assessed the potential role of the type of lipids used in parenteral nutrition (PN) admixtures on the quantity of DEHP leached out from PVC-based tubings. ${ }^{27}$ After a 24-hour exposure period, the olive oil-based emulsion Clinoleic ${ }^{\circledR} 20 \%$ (Baxter, Maurepas, France) leached the most DEHP $(65.8 \mu \mathrm{g} / \mathrm{mL})$, followed by the fish oil-based emulsion Omegaven ${ }^{\circledR}$ (Fresenius-Kabi, Bad Homburg, Germany) $(37.8 \mu \mathrm{g} / \mathrm{mL})$. The soybean oil-based emulsions Intralipid ${ }^{\mathbb{R}}$ $20 \%$ (Fresenius-Kabi, Sèvres, France); Medialipide ${ }^{\circledR}$ $20 \%$ (B. Braun Medical, Boulogne, France); Lipidem ${ }^{\circledR} 20 \%$ (B. Braun Medical, Boulogne, France); Structolipid ${ }^{\circledR} 20 \%$ (Fresenius-Kabi, Bad Homburg, Germany) exhibited similar performances, with DEHP in the emulsion measured at 27.3, 27.8, 23.6, and $19.6 \mu \mathrm{g} / \mathrm{mL}$, respectively. In April 2013, the State Food and Drug Administration in the People's Republic of China recommended that PVC-based bags not be used for lipid emulsion infusion. However, many hospitals still use PVC-based bags for preparing PN. Total PN mixtures containing fat emulsions should be stored in ethyl vinyl acetate bags rather than PVC packs. ${ }^{28}$ The equipment management committee in SAHZU has introduced an ethyl vinyl acetatebased PN infusion bag in January 2014.

\section{Pore size on in-line filters}

Special requirements of pore size on in-line filters are noted in prescribing information for some medications. Paclitaxe ${ }^{15}$ is one of the most effective anticancer drugs. To prevent hazards associated with IV administration, which include the formation of microbubbles, microbiological contamination, and particulate matter, the suppliers recommend that an in-line IV filter $(0.22 \mu \mathrm{m}$ pore size $)$ should be used during the infusion of the chemotherapeutic agent. Admixtures of IV Prevacid ${ }^{\circledR}$ (lansoprazole for injection; Takeda Pharmaceuticals, Osaka, Japan) should be administered intravenously using the in-line filter provided (1.2 $\mu \mathrm{m}$ pore size). The filter must be used to remove precipitate that may form when the reconstituted drug product is mixed with IV solutions. ${ }^{29}$ However, using such filters will obviously decrease the infusion speed and this will reduce nurse's compliance with the medication administration instruction stated in the package insert..$^{30}$ IV Prevacid is not available in the Chinese market, but there is a domestic generic formulation (Aoweijia ${ }^{\circledR}$ ) (Jiangsu Aosaikang Pharmaceutical Co, Ltd, Nanjing, People's Republic of China). The formulation package does not contain a special infusion set. PIVAS in SAHZU dispenses lansoprazole admixtures by matching a bag of prepared lansoprazole infusion with a special infusion set. Additionally, the label on the infusion bag clearly notes the relevant precautions. PIVAS pharmacists believed ward nurses would certainly use the specific infusion sets prior to IV administration; however, during an on-the-spot inspection in October 2013, pharmacists astonishingly found that many specific lansoprazole infusion sets appeared in some wards without accompanying medications, and that nurses demonstrated poor adherence to using the designated infusion sets. Some nurses were still using the common infusion set with a $15 \mu \mathrm{M}$ in-line filter. Further education was introduced and performance management was strengthened. At the end of November 2013, the adherence rate was $100 \%$.

Essential medicines, as defined by the World Health Organization, are "those that satisfy the priority health care needs of the population. They are selected with due regard to public health relevance, evidence on efficacy and safety, and comparative cost-effectiveness." ${ }^{24}$ Taking into account that IV omeprazole and IV pantoprazole are essential medicines in the People's Republic of China and that IV administration of these two medications does not need special infusion sets, pharmacists in SAHZU recommended them as alternatives to IV lansoprazole.

\section{Types of vascular access}

There are four main types of vascular access, including scalp needle, central venous catheter, peripherally inserted central catheter (PICC) and peripheral vein indwelling needle. A central venous catheter is an indwelling IV device that is inserted into a vein of the central vasculature. PICC is a form of IV access that can be used for a prolonged period of time (eg, for long chemotherapy regimens, extended antibiotic therapy, 
or total PN). Vascular access management is a specialized skill performed by IV practitioners who have demonstrated the required competencies.

SAHZU established a multidisciplinary IV team in 2010 and began to perform continuous quality improvements in infusion therapy management. An evidence-based clinical pathway of vascular access selection was drafted to govern the IV administration. Training and tracing were organized by the division of nursing. The plan-do-check-act and quality control circle approaches were implemented to decrease the occurrence of infusion therapy-related complications and increase the inclusion rate of clinical pathways. From 2009 to 2012, the relative percentage of PICC use clearly increased $(12 \%$ to $26 \%, P<0.01)$ and that of scalp needle usedramatically decreased $(24 \%$ to $3 \%, P<0.01)$ (Figure 1$)$. A sustained growth was observed with PICC procedures during 2009 to 2012. The number of patients receiving PICC using ultrasound guidance in 2012 was 7.6 times that in 2009, and the number of patients receiving PICC without ultrasound guidance in 2012 was 1.6 times the value in 2009 (Figure 2). The total number of infusions in 2012 was 2.92 million, slightly higher than the 2011 figure (ie, 2.90 million). However, encouragingly, the number of cases of complications related to infusion therapy in 2012 was less than that in 2011 (513 versus $800, P<0.01$ ) (Figure 3 ). The change in the number of complications indicated that the endeavor of the IV team was effective.

\section{Management of electronic infusion pumps}

An infusion pump is used to deliver controlled doses of medications and nutrition to patients. In contrast to many infusion pumps designed for bedbound patients, an ambulatory infusion pump allows a patient to move around while the pump is in use. All clinical practitioners should be competent and confident in the use of the device and in the procedure. It is their responsibility to ensure correct and safe infusion therapy.

There are electronic pumps and non-electronic devices used for infusion of IV medications. Baxter Elastomeric Pumps (Baxter Corporation, Mississauga, ON, Canada) are non-electronic medication pumps designed to provide ambulatory infusion therapy. The elastomeric technology promotes patient recovery and improves patient quality of life by allowing ambulatory treatment without the inconvenience of programming, power sources, or alarms. The pumps had been used in SAHZU before the end of August 2010. However, such infusors lost out in a provincial competitive bidding program for disposable aseptic medical instruments in 2010 and they were not permitted to be used in hospitals in the People's Republic of China's Zhejiang Province. An alternative electronic infusion pump was then introduced into SAHZU.

It is necessary to efficiently manage the use of electronic infusion pumps, especially for administering infusion of high-alert medications. One of the US National Patient Safety Goals promulgated by The Joint Commission on Accreditation of Healthcare Organizations is to "improve the safety of using infusion pumps" 31 by ensuring that pumps are protected against free-flow, which refers to the uncontrolled delivery of an infusion to a patient when a controlled or metered delivery was intended. ${ }^{31}$

The Institute for Safe Medication Practices (ISMP) Canada published a root cause analysis of a fluorouracil incident on May 22, 2007. The event was as follows: on
A

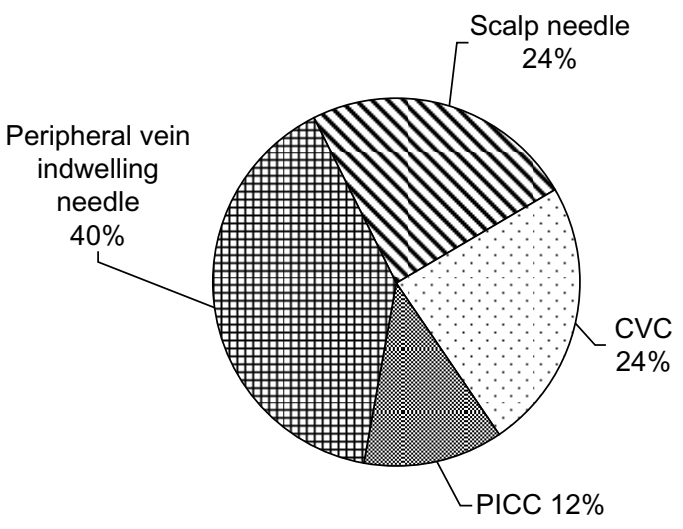

Before intervention
B

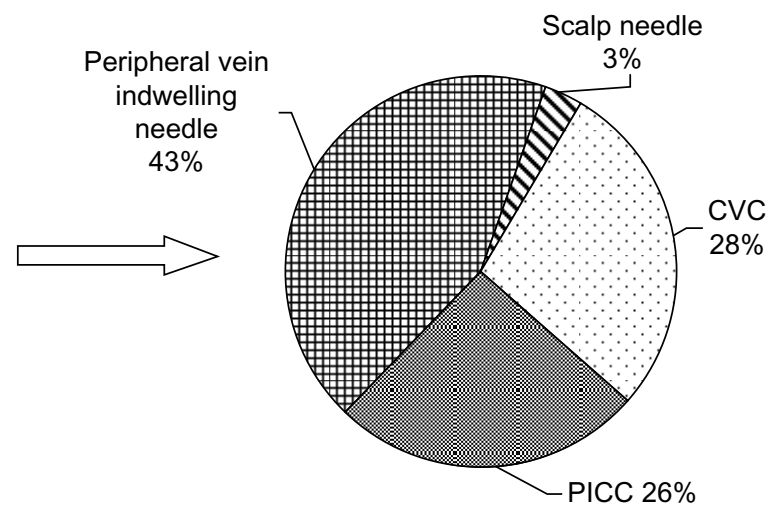

After intervention

Figure I Relative percentages of infusion devices used before (A) and after (B) the intravenous team's intervention (2009 versus 2012). Abbreviations: CVC, central venous catheter; PICC, peripherally inserted central catheter. 


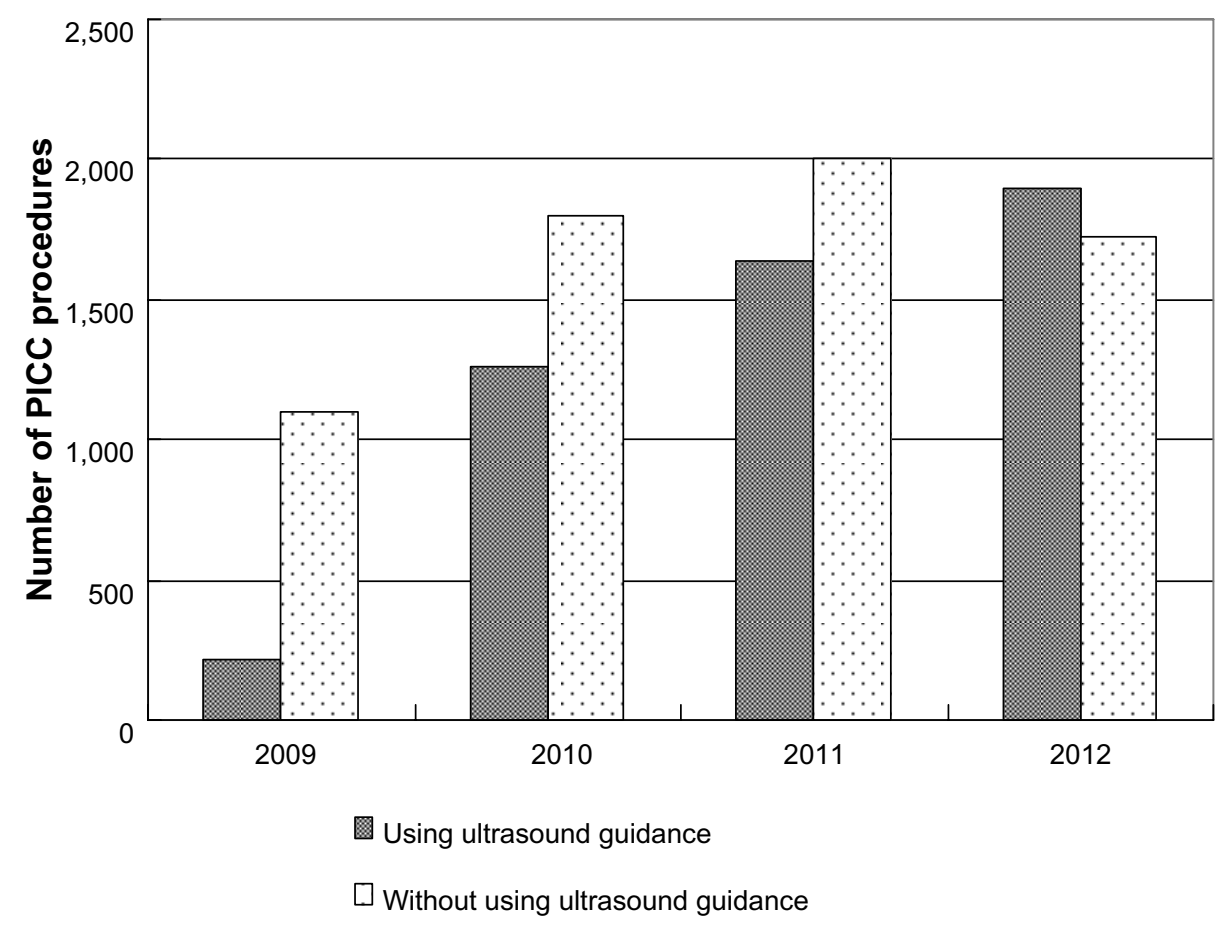

Figure 2 Number of PICC procedures before and after the intravenous team's intervention.

Abbreviation: PICC, peripherally inserted central catheter.

July 31, 2006, a 43-year-old woman with nasopharyngeal cancer received, over 4 hours, an infusion of fluorouracil $(5,250 \mathrm{mg})$ that was intended to be administered over 4 days. Eight incidents similar to the one under analysis were also summarized in that report. ${ }^{32}$ On September 23, 2010, a similar fluorouracil incident occurred in SAHZU. An infusion of fluorouracil $(3,500 \mathrm{mg})$ that was intended to be administered over 40 hours at a speed of $4 \mathrm{~mL} /$ hour was mistakenly given to a patient without installing an electronic driver (Figure 4). All fluid entered the systemic circulation of the patient in less than 30 minutes under the action of gravity. Fortunately, the patient recovered after the multidisciplinary team's immediate intervention.

As Reason said, the human error problem can be viewed in two ways: the person approach and the system approach. ${ }^{33}$ The person approach focuses on the errors of individuals, blaming them for forgetfulness, inattention, or moral weakness. The system approach concentrates on the conditions under which individuals work and tries to build defenses to avert errors or mitigate their effects. There are numerous reasons why the fluorouracil incident to the 43-year-old woman in the ISMP report occurred.$^{32}$ Reason's Swiss cheese model shows

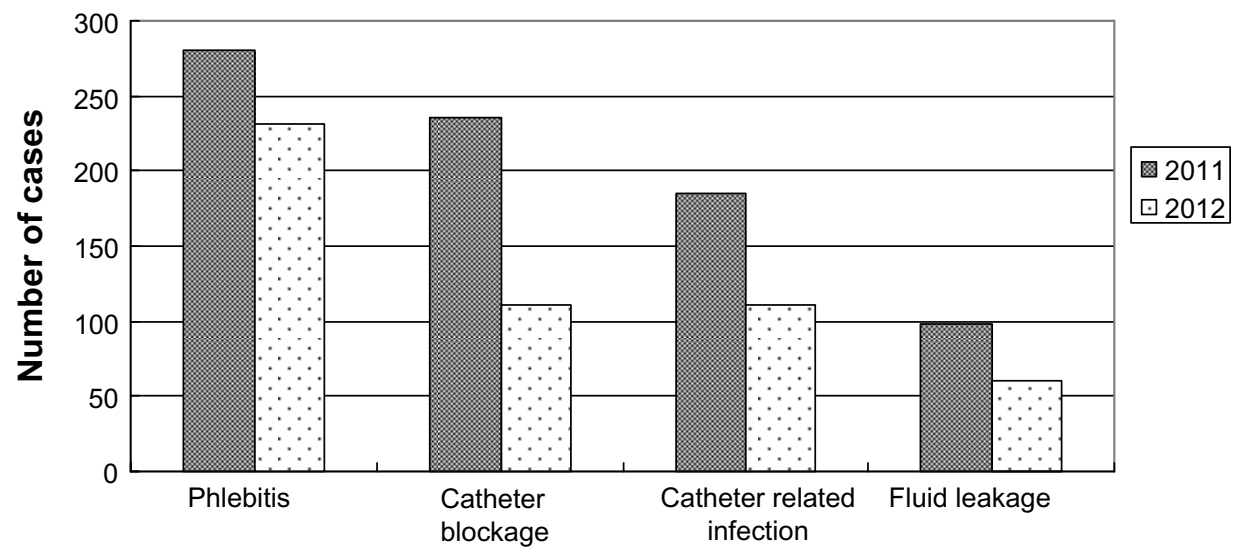

Figure 3 Cases of complications in infusion therapy in $20 \mathrm{II}$ and 2012. 

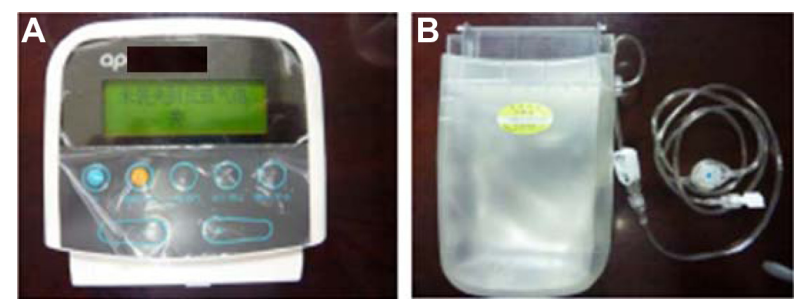

Figure 4 Driver (A) and drug container (B) of ambulatory infusion pumps for fluorouracil infusion.

Note: Apon ${ }^{\circledR}$; Nantong Aipu Medical Instrument Co., Ltd., Nantong, People’s Republic of China.

how defenses, barriers, and safeguards may be penetrated by an accident trajectory. ${ }^{33} \mathrm{~A}$ fishbone analysis conducted in SAHZU described all defects in the aspects of operation procedure, communication, personnel, and equipment management. An orthopedic surgeon receiving rotation in a general surgery ward wrote a physician order of fluorouracil infusion in the circumstance of being unfamiliar with the pump-based chemotherapy regimen. The nurse concerned had never administered fluorouracil via electronic-driven pump to patients. The training of use of new electronic infusion pumps organized by the engineering department did not cover the ward that experienced the accident. Standard operation procedure on management and use of the ambulatory infusion pump was unavailable at that time. A multidisciplinary policy, defining the responsibilities of PIVAS, the division of nursing, the division of medical administration, the engineering department, and the quality management office was then formulated to address all the procedures of electronic pump-based infusion therapy, including prescribing, transcribing, prescription auditing, preparation, packaging, logistic delivery, dosing, monitoring, driver maintenance, and training. Thereafter, no similar adverse events occurred.

Additionally, there were five adverse events related with early or delayed termination of fluorouracil infusions via ambulatory pumps during 2010-2011. Continuous fluorouracil infusion is usually administered at a speed of $4 \mathrm{~mL} /$ hour. Although double-checking is always performed during the preparation of pump-based infusion admixtures, a $4 \mathrm{~mL}$ error in fluid volume will cause a 1-hour deviation from the schedule, which brings about potential medical disputes between hospitals and patients. PIVAS pharmacists invented a weighing method whereby an infusion pump is weighed by an electronic balance, with the weight value expected to fall within an accepted range. So far, there have been no adverse events related with early or delayed termination of fluorouracil infusion. Our experience indicates that accuracy estimations of infusion admixture using weighing method are pragmatic.

\section{Infusion tube management}

Infusion switches carry a potential risk of incident, especially for high-alert medications. A medication incident in SAHZU in 2010 gave a profound lesson. A prefilled propofol syringe (Diprivan 1\% infusion kit; Astra Zeneca, Södertälje, Sweden) was being given to an intensive care unit patient at a speed of $5 \mathrm{~mL} /$ hour and was paused by a nurse. Then, infusion of the mucolytic drug ambroxol via micro-pump at $20 \mathrm{~mL} /$ hour passed through the extension tube previously used for the propofol infusion. The patient suddenly experienced severe oversedation and finally died. A multidisciplinary team discussion indicated that the unaltered extension tube was the culprit of the fatal event. The volume of residual propofol infusion in that extension tube was measured as approximately $6 \mathrm{~mL}$ and this dose $(60 \mathrm{mg})$ given at $20 \mathrm{~mL} /$ hour was fatal to the patient. The incident involved temporary cessation of propofol infusion without physician orders, ignorance of risk of improper infusion switch involving high-alert medication, and poor awareness of the relationship between infusion speed and safety.

Accidental infusion of propofol can be fatal because it causes severe respiratory depression or hypotension. We offer the following suggestions to help avoid a similar experience:

1. Use a Y-tube positioned close to the injection site because propofol infusion $(10 \mathrm{mg} / \mathrm{mL})$ may be administered at the same time as a $5 \%$ glucose or $0.9 \%$ sodium chloride solution by Y-tube.

2. Do not pause the propofol infusion without physician orders.

3. Do not improperly switch the infusion tube.

4. Only administer propofol when resuscitation equipment is immediately available.

\section{Leakage of infusion solution around syringe needle}

When drugs are drawn up in a syringe, it is a general understanding in Western countries that this is done in a Leur lock syringe to which a syringe cap is fitted. When the drug is due to be given, the nurse undoes the syringe cap and attaches the syringe to the vascular access device. Under this operating procedure, no liquid leakage will occur. However, a Luer slip syringe, rather than a Luer lock syringe, is predominately applied in Chinese hospitals, partly due to the fact that Luer slip 


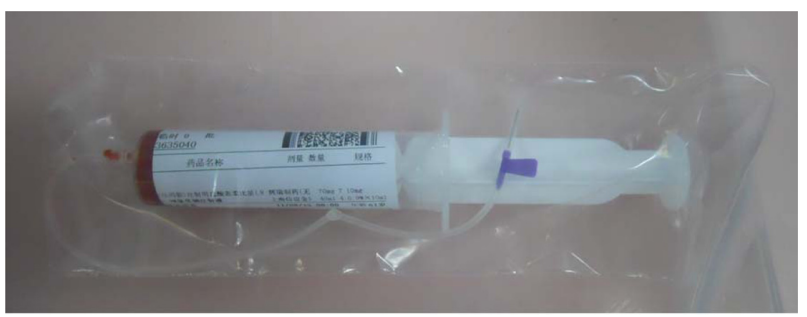

Figure 5 An illustration of a packaging method to overcome liquid leakage of chemotherapeutic infusion around the syringe needle.

Notes: A disposable infusion pipe is connected to a $50 \mathrm{~mL}$ syringe, making a slipknot on the connecting pipe. The combined devices are packaged into an aseptic sealed plastic bag.

syringes tend to be cheaper than Leur lock syringes. Therefore, liquid leakage around the syringe needle usually occurs during the logistic delivery of Luer slip syringe-based chemotherapeutic infusion from PIVAS to wards because the plunger of the syringe can be pushed by other items. For the sake of reducing occupational exposure to chemotherapy drugs, the leakage problem must be solved. PIVAS staff invented an effective technique that uses a disposable infusion pipe connected to a $50 \mathrm{~mL}$ syringe, making a slipknot on the connecting pipe, and packaging the combined devices into an aseptic sealed plastic bag (Figure 5). We compared the two packaging methods; that is: 1 ) a $50 \mathrm{~mL}$ syringe capped with a size 9 needle (outer diameter $0.9 \mathrm{~mm})(\mathrm{n}=100)$; and 2) a $50 \mathrm{~mL}$ syringe connected with a disposable infusion pipe with a slipknot $(n=100)$. The occurrence of liquid leakage was almost abolished by using the new method ( $1 \%$ versus $30 \%, P<0.001)$.

\section{Conclusion}

In this article, we summarized experiences in injection device-related risk management toward safe administration of medications. Injection device-related near misses and adverse events often involve improper selection of needle diameter for subcutaneous injection, material of infusion sets and pore size of in-line filter, complications associated with vascular access, incidents induced by absence of efficient electronic pump management and infusion tube management, and liquid leakage of chemotherapeutic infusion around the syringe needle. Safe injection drug use may be enhanced by multidisciplinary collaboration, especially among pharmacists and nurses; drafting of clinical pathways in selection of vascular access; application of approaches such as root cause analysis using a fishbone diagram; plan-do-check-act and quality control circle; and construction of a culture of spontaneous reporting of near misses and adverse events. Pharmacists must be professional in regards to medication management and use. The depth, breadth, and efficiency of cooperation between nurses and pharmacists are pivotal to injection safety.

\section{Acknowledgments}

The authors thank Zheng-Rong Li for reporting medicationrelated near misses, and Rui-YI Zhao for providing partial data on experience of a nurse-led PICC line service.

\section{Disclosure}

The authors report no conflicts of interest in this work.

\section{References}

1. Quinn C. Infusion devices: risks, functions and management. Nurs Stand. 2000;14:35-41.

2. Bates DW, Spell N, Cullen DJ, et al. The costs of adverse drug events in hospitalized patients. Adverse Drug Events Prevention Study Group. JAMA. 1997;227:307-311.

3. Bates DW, Cullen DJ, Laird N, et al. Incidence of adverse drug events and potential adverse drug events. Implications for prevention. ADE Prevention Study Group. JAMA. 1995;274:29-34.

4. Keay S, Callander C. The safe use of infusion devices. Continuing Education in Anaesthesia, Critical Care and Pain. 2004;4:81-85.

5. Moureau N. Safe patient care when using vascular access devices. Br J Nurs. 2013;22:S14, S16, S18 passim.

6. Gabriel J. The use of subcutaneous infusion in medication administration Br J Nurs. 2013;22:S6, S8, S10 passim.

7. Arendt-Nielsen L, Egekvist H, Bjerring P. Pain following controlled cutaneous insertion of needles with different diameters. Somatosens Mot Res. 2006;23:37-43.

8. Iwanaga M, Kamoi K. Patient perceptions of injection pain and anxiety: a comparison of NovoFine 32-gauge tip $6 \mathrm{~mm}$ and Micro Fine Plus 31-gauge 5mm needles. Diabetes Technol Ther. 2009;11:81-86.

9. Juul KA, Bengtsson H, Eyving B, et al. Influence of hypodermic needle dimensions on subcutaneous injection delivery - a pig study of injection deposition evaluated by CT scanning, histology, and backflow. Skin Res Technol. 2012;18:447-455.

10. Enantone ${ }^{\circledR}$ (leuprolide acetate microspheres for injection) [package insert]. Osaka Japan: Takeda Pharmaceutical Company Limited; 2012.

11. Cilurzo F, Selmin F, Minghetti P, et al. Injectability evaluation: an open issue. AAPS PharmSciTech. 2011;12:604-609.

12. Demoré B, Vigneron J, Perrin A, Hoffman MA, Hoffman M. Leaching of diethylhexyl phthalate from polyvinyl chloride bags into intravenous etoposide solution. J Clin Pharm Ther. 2002;27:139-142.

13. Takehisa H, Naoko E, Masahiko S, et al. Release behavior of diethylhexyl phthalate from the polyvinyl-chloride tubing used for intravenous administration and the plasticized PVC membrane. Int $J$ Pharm. 2005;297:30-37

14. Pearson SD, Trissel LA. Leaching of diethylhexyl phthalate from polyvinyl chloride containers by selected drugs and formulation components. Am J Hosp Pharm. 1993;50:1405-1409.

15. TAXOL ${ }^{\circledR}$ (paclitaxel) injection. Bristol-Myers Squibb Company, NJ, USA.[last reviewed April, 2011] . Available from: http://packageinserts. bms.com/pi/pi_taxol.pdf. Accessed December 4, 2013.

16. Sandimmune ${ }^{\circledR}$ (cyclosporine injection). [webpage on the Internet]. New York, NY: RxList ${ }^{\circledR}$ [Last reviewed on May 17, 2013]. Available from: http://www.rxlist.com/sandimmune-drug/medication-guide.htm. Accessed December 4, 2013.

17. Vumon ${ }^{\circledR}$ (teniposide injection). [webpage on the Internet]. New York, NY: RxList ${ }^{\circledR}$ [Last reviewed on November 7, 2011]. Available from http://www.rxlist.com/vumon-drug/indications-dosage.htm. Accessed December 4, 2013. 
18. Kim SC, Yoon HJ, Lee JW, Yu J, Park ES, Chi SC. Investigation of the release behavior of DEHP from infusion sets by paclitaxel-loaded polymeric micelles. Int J Pharm. 2005;293:303-310.

19. Bagel-Boithias S, Sautou-Miranda V, Bourdeaux D, Tramier V, Boyer A, Chopineau J. Leaching of diethylhexyl phthalate from multilayer tubing into etoposide infusion solutions. Am J Health Syst Pharm. 2005;62:182-188

20. McLeod AG, Walker IR, Zheng S, Hayward CP. Loss of factor VIII activity during storage in PVC containers due to adsorption. Haemophilia. 2000;6:89-92.

21. NIMOTOP ${ }^{\circledR}$. Bayer Australia Ltd. [last reviewed April 1, 2011]. Available from: http://www.bayerresources.com.au/resources/uploads/PI/ file9406.pdf. Accessed December 4, 2013.

22. Treleano A, Wolz G, Brandsch R, Welle F. Investigation into the sorption of nitroglycerin and diazepam into PVC tubes and alternative tube materials during application. Int J Pharm. 2009;369:30-37.

23. Trissel LA, Xu QA, Baker M. Drug compatibility with new polyolefin infusion solution containers. Am J Health Syst Pharm. 2006;63: 2379-2382.

24. Essential medicines. [webpage on the Internet]. Available from: http:// www.who.int/topics/essential_medicines/en/. Accessed December 4, 2013.

25. Sattler A, Jage J, Krämer I. Physico-chemical stability of infusion solutions for epidural administration containing fentanyl and bupivacaine or lidocaine. Pharmazie. 1998;53:386-391.

26. Henton DH, Merritt RJ. Vitamin A sorption to polyvinyl and polyolefin intravenous tubing. JPEN J Parenter Enteral Nutr. 1990;14:79-81.
27. Bagel S, Dessaigne B, Bourdeaux D, et al. Influence of lipid type on bis (2-ethylhexyl)phthalate (DEHP) leaching from infusion line sets in parenteral nutrition. JPEN J Parenter Enteral Nutr. 2011;35: $770-775$.

28. Kambia K, Dine T, Gressier B, et al. Evaluation of childhood exposure to di(2-ethylhexyl) phthalate from perfusion kits during long-term parenteral nutrition. Int J Pharm. 2003;262:83-91.

29. Prevacid IV. [webpage on the Internet]. New York, NY: RxList ${ }^{\circledR}$ [last reviewed November 7, 2007]. Available from: http://www.rxlist.com/prevacid-iv-drug/indications-dosage.htm. Accessed December 4, 2013.

30. IV Prevacid ${ }^{\circledR}$ (lansoprazole for injection). [webpage on the Internet]. New York, NY: RxList ${ }^{\circledR}$ [Last reviewed on July 11, 2013]. Available from: http://www.rxlist.com/prevacid-iv-drug.htm. Accessed December 4, 2013.

31. [No authors listed]. JCAHO's National Patient Safety Goal for infusion pump free-flow protection: ECRI's assessment of the protection offered by general-purpose, PCA, and ambulatory pumps. Health Devices. 2004;33:430-435.

32. Fluorouracil Incident Root Cause Analysis. Toronto, ON: Institute for Safe Medication Practices Canada ${ }^{\circledR} ; 2007$. Available from: https://www. ismp-canada.org/download/reports/FluorouracilIncidentMay2007.pdf. Accessed December 4, 2013.

33. Reason J. Human error: models and management. BMJ. 2000;320: $768-770$.
Therapeutics and Clinical Risk Management

\section{Publish your work in this journal}

Therapeutics and Clinical Risk Management is an international, peerreviewed journal of clinical therapeutics and risk management, focusing on concise rapid reporting of clinical studies in all therapeutic areas outcomes, safety, and programs for the effective, safe, and sustained use of medicines. This journal is indexed on PubMed Central, CAS,

\section{Dovepress}

EMBase, Scopus and the Elsevier Bibliographic databases. The manuscript management system is completely online and includes a very quick and fair peer-review system, which is all easy to use. Visit $\mathrm{http}: / /$ www.dovepress.com/testimonials.php to read real quotes from published authors. 